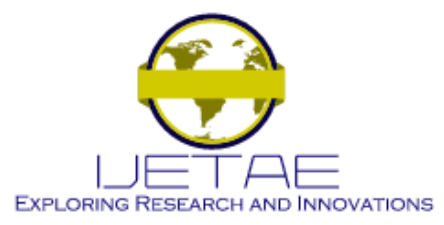

International Journal of Emerging Technology and Advanced Engineering

Website: www.ijetae.com (ISSN 2250-2459, ISO 9001:2008 Certified Journal, Volume 11, Issue 04, April 2021)

Manuscript Received: 02 March 2021, Received in Revised form: 10 April 2021, Accepted: 21 April 2021

\title{
Development of Oral Healthcare Application for Improving Recognition Function to Prevent Elderly Dementia
}

\author{
In-Ae Kang ${ }^{1}$, Kyung-Oh Lee ${ }^{2}$, Yong-Keum Choi ${ }^{3}$ \\ ${ }^{1,2}$ Department of Computer Convergence Electronics, Sun-Moon University \& 70, Sunmoon-ro 221beon-gil, Tangjeong-myon, \\ Asan-si, Chungcheongname-do, Republic of Korea
}

\begin{abstract}
Korea and Japan are the countries with more than $30 \%$ of the population aged 60 or over in 2019, and Korea is progressing its aging speed faster than Japan. Oral healthcare in the elderly is a fundamental component of the whole health and has a significant impact on the quality of life. Accordingly, there is an urgent interest and effort for improving oral healthcare and improving the quality of life for the elderly. Due to the lack of economic power and low education levels, the number of dental visits by the elderly has dropped significantly. Therefore, developing an application for oral healthcare for the elderly not only helps to keep oral healthcare on their own but also prevents dementia, thus reducing the social cost of dementia. This mobile application is based on the findings that it can activate the cognitivebehavioural function, prevent dementia, or slow the progression of dementia by strengthening chewing function and oral muscle function exercise of the elderly. This application is composed of a content utilization module and oral healthcare diagnostic module and used Android Jellybean 4.1, Android SDK, Cordova, Materialize CSS, Sublime Editor, Windows 10 for mobile application development.
\end{abstract}

Keywords - elderly people, Oral web system, Dental Application, Dementia prevention, older adults Dental care.

\section{INTRODUCTION}

The life expectancy of the elderly is increasing rapidly due to the recent development of medical technology.

[1] According to statistics from the National Statistical Office, the average life expectancy of Koreans is $79.5 \%$ and is extended by $5 \%$ every year and by 2050 , the average life expectancy is expected to be $84.2 \%$ for men and $90 \%$ for women, and $87.1 \%$ for average.

As the aging society comes, various social problems are occurring and among them, dementia, one of the representative senile diseases, cannot be excluded. In addition to mental dysfunction due to simple brain function dementia, its symptoms are severely limiting interpersonal and social activities due to urinary problems and the difficulties of daily life. Also, [7] Dementia is a disease that causes a lot of pains for the patients and their families in the long-term and deteriorates the quality of life for all of them.
Current medical techniques do not provide a clear treatment for dementia, so the only way to alleviate the symptoms is through prevention and rehabilitation. Until now, dementia rehabilitation facilities have been difficult to manage efficiently due to problems such as cost, and lack of patient data management. To solve these problems, this study developed a mobile application that can make a database of medical information and produce oral healthrelated contents to be serviced on a smartphone, which is convergence research of IT and dental hygiene.

[8], [9] Because dementia and oral healthcare are deeply related, strengthening chewing function and oral muscle exercise in the elderly can activate cognitive-behavioural functions to prevent dementia or slow the progression of dementia. This application can first survey to diagnose the degree of dementia and manage individual patient data. Also, a game needed to prevent dementia was produced, and an oral Pilate's video that elderly people can watch and follow was made available on a smartphone. The application eliminated the need for older senior citizens and elderly people with dementia to travel long distances to receive this service, and they can easily use the system anytime, anywhere.

\section{Page Layout}

An application called 'Dementia Check', a dementia diagnosis program, developed by the Ministry of Health and Welfare, displays customized dementia prevention rules according to the results of dementia diagnosis. It also provides patient care and counseling services for caring services, provides information on dementia facilities, and enables real-time patient location searches to prevent the missing of the elderly with dementia.

Brain Health Care Application [10] developed by Chosun University uses a method to prevent digital dementia and implements a game that remembers names and phone numbers of acquaintances to improve memory. However, the difficulty level of the game is somewhat hard for dementia elderly to medically proceed with the program. 


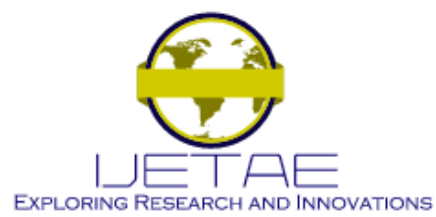

International Journal of Emerging Technology and Advanced Engineering

Website: www.ijetae.com (ISSN 2250-2459, ISO 9001:2008 Certified Journal, Volume 11, Issue 04, April 2021)

The smartphone application developed in Kim Hyemyung's paper of Gimpo University [11] can determine dementia through the MMSE test and it is the guide content to the relevant dementia support center after diagnosis and stages of dementia. Other applications available on the Google Play Store include seniors' playground, dementia prevention, king of numbers, and memory game for preventing dementia. In general, all mobile applications consist of programs that prevent and delay while providing games such as simple addition and crossword matching to improve memory, focusing on the simple brain function of dementia.

Oral healthcare application for improving recognition function to prevent elderly dementia, developed in this paper, not only improves memory problems and cognitive function but also researches the relationship between dementia and oral healthcare and it is composed of various contents including oral Pilate's video that cannot be seen in other applications. The application also determines the patient's condition and stores and manages the patient's data in a database so that the content can be used according to the individual's level of dementia. Also, considering that the user is a dementia patient or an elderly person, the content is configured to be easily used.

The following is the comparison between the application features developed in this paper and the existing applications.

TABLE I

COMPARISON BETWEEN THE APPLICATION OF IMPROVEMENT OF Cognitive Function For The Prevention Of Dementia In ELDERLY AND OTHER APPLICATIONS

\begin{tabular}{|l|l|l|l|l|l|}
\hline & $\begin{array}{c}\text { Deme } \\
\text { ntia } \\
\text { check }\end{array}$ & $\begin{array}{c}\text { Brain } \\
\text { health }\end{array}$ & $\begin{array}{c}\text { Smart } \\
\text { phone } \\
\text { applic } \\
\text { ation }\end{array}$ & $\begin{array}{c}\text { Deme } \\
\text { ntia } \\
\text { Preve } \\
\text { ntion }\end{array}$ & $\begin{array}{c}\text { Elderly } \\
\text { Dement } \\
\text { ia } \\
\text { applicat } \\
\text { ion }\end{array}$ \\
\hline $\begin{array}{l}\text { Dementia } \\
\text { diagnosis } \\
\text { expertise }\end{array}$ & $\mathrm{o}$ & $\mathrm{x}$ & $\mathrm{O}$ & $\mathrm{x}$ & $\mathrm{O}$ \\
\hline $\begin{array}{l}\text { Various } \\
\text { contents }\end{array}$ & $\mathrm{x}$ & $\mathrm{x}$ & $\mathrm{x}$ & $\mathrm{x}$ & $\mathrm{O}$ \\
\hline $\begin{array}{l}\text { Simple } \\
\text { operation }\end{array}$ & $\mathrm{O}$ & $\mathrm{x}$ & $\mathrm{O}$ & $\mathrm{O}$ & $\mathrm{O}$ \\
\hline $\begin{array}{l}\text { Improve } \\
\text { memory }\end{array}$ & $\mathrm{x}$ & $\mathrm{O}$ & $\mathrm{x}$ & $\mathrm{O}$ & $\mathrm{O}$ \\
\hline $\begin{array}{l}\text { Personal } \\
\text { data } \\
\text { manageme } \\
\text { nt }\end{array}$ & $\mathrm{x}$ & $\mathrm{x}$ & $\mathrm{x}$ & $\mathrm{x}$ & $\mathrm{O}$ \\
\hline
\end{tabular}

As can be seen from the table above, the application developed in this paper can diagnose dementia professionally, provide various contents, simplify the operation, retain memory enhancement contents, and manage the patient's data, and it has a characteristic of combining other existing studies.

\section{IMPLEMENTATION}

\section{A. Application Analysis}

This study produced various contents for the development of an application for the prevention of dementia and improvement of oral healthcare, and this application provides medical services with information technology (IT). For this application, dental hygienists participated and provided the accumulated knowledge and the information can be easily used by general users anytime, anywhere through this application and the mobile application development technology, database construction technology, content production, and service technology were all used infusion for this application.

An overview of the system to be developed is shown in Figure 1 below.

- Mobile Application was developed through Android Studio and used NODC to transmit or store data.

- Finally, data is stored in the database via MySQL.

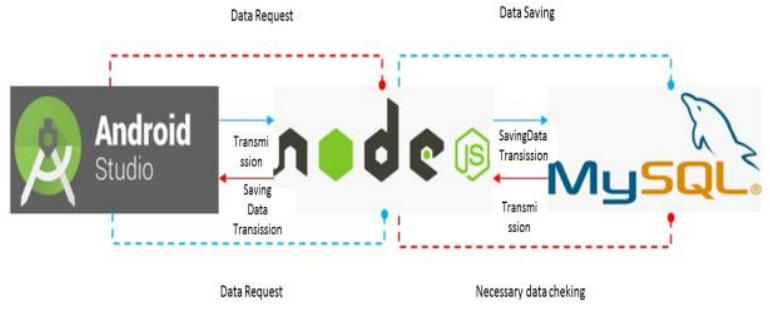

Figure-1. System Overview

The detailed configuration of the system is as follows.

- Mobile Application consists of educational content utilization module, oral healthcare diagnostic module, and expert advisory module.

- The technologies for developing the mobile application include Android Jellybean 4.1, Android SDK, Cordova, Materialize CSS, Sublime Editor, Windows 10, etc.

- XAMPP 3.2.2, PHP 7.1.6, Apache 2.4.25, Mysqlnd 5.0 .12 , etc. are used to build a server for content services.

- DataBase includes multimedia content related to elderly oral healthcare, diagnostic data related to elderly oral healthcare, data related to elderly personal health, and oral specialist and dental data. 


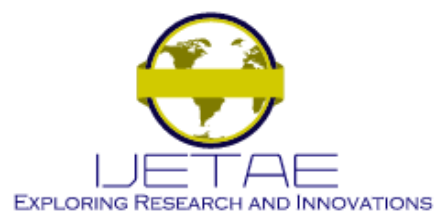

International Journal of Emerging Technology and Advanced Engineering Website: www.ijetae.com (ISSN 2250-2459, ISO 9001:2008 Certified Journal, Volume 11, Issue 04, April 2021)

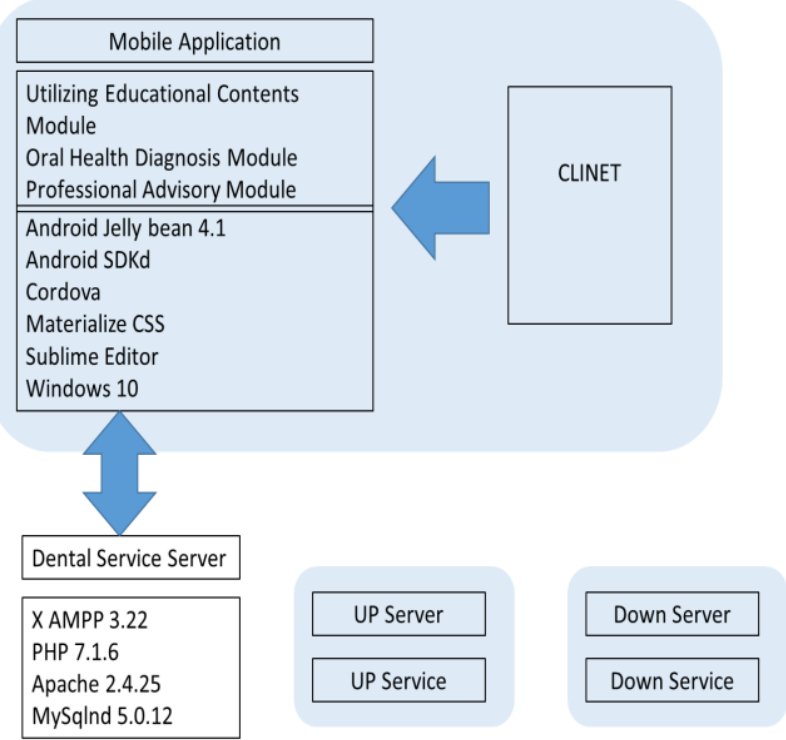

Figure-2. Detailed System Configuration

\section{B. Application Design Planning}

The structure diagram of the Mobile Application developed in this paper is as follows.

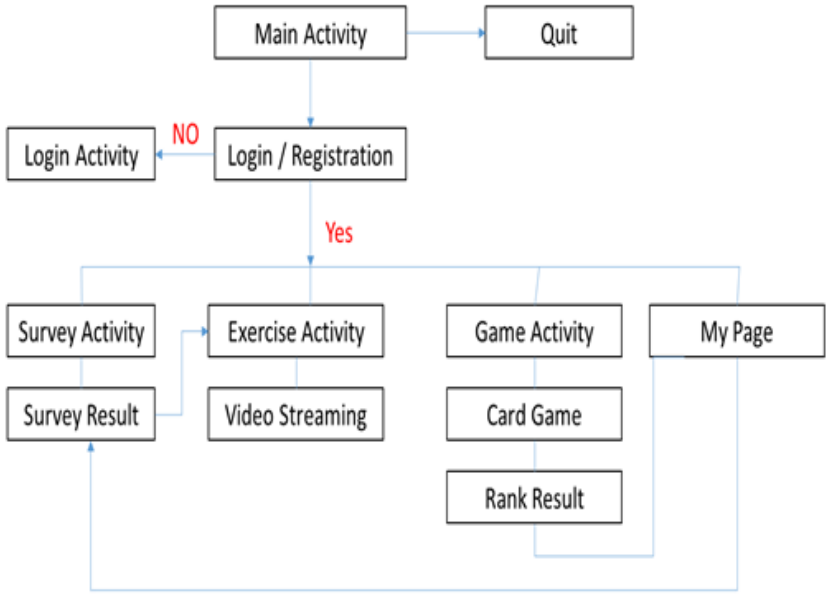

Figure-3 Application Structure

Since the data is managed in the database to manage the elderly oral status and dementia progression, the dementia diagnostic test, dementia prevention game, and oral Pilates videos can be used after login.

\section{Screen Analysis of Mobile Application}

- This Figure-3: This screen allows you to use 4 functions (Dementia Diagnosis Test, My Page, Oral Pilates Image, and Dementia Prevention Game) and if the main screen is not logged in, the function cannot be used and the screen switches to the login screen.

- Figure-4: The user must $\log$ in to use the application. The ID and password are stored in the database and if you click the Login button, the ID and password are being matched.

- Figure-5: This function is used when the user forgets their ID and password.

- Figure-6: This allows the user to enter the necessary information when registering.

- Figure-7: This screen shows the result page after the dementia diagnosis and oral healthcare status test and in the upper left corner of the page, the characters that match the current user's score and level are shown. The right side of the screen shows the user's brain stage and the bottom shows the brain stage in the form of a bar.

- Figure-8: This page shows the results of the diagnosis of dementia, the history of dementia prevention games, and the user's subscription information.

- Figure-9: After dementia testing, the user can watch and follow four oral Pilates training videos to prevent and relieve dementia.

- Figure-10: This is a matching card game where you can press the Start button to see a mix of cards for 5 seconds. If you are right for the flipped-over card, you get 10 points, and if not, you get -5 points. Scores are posted to the database and your ranking is shown.

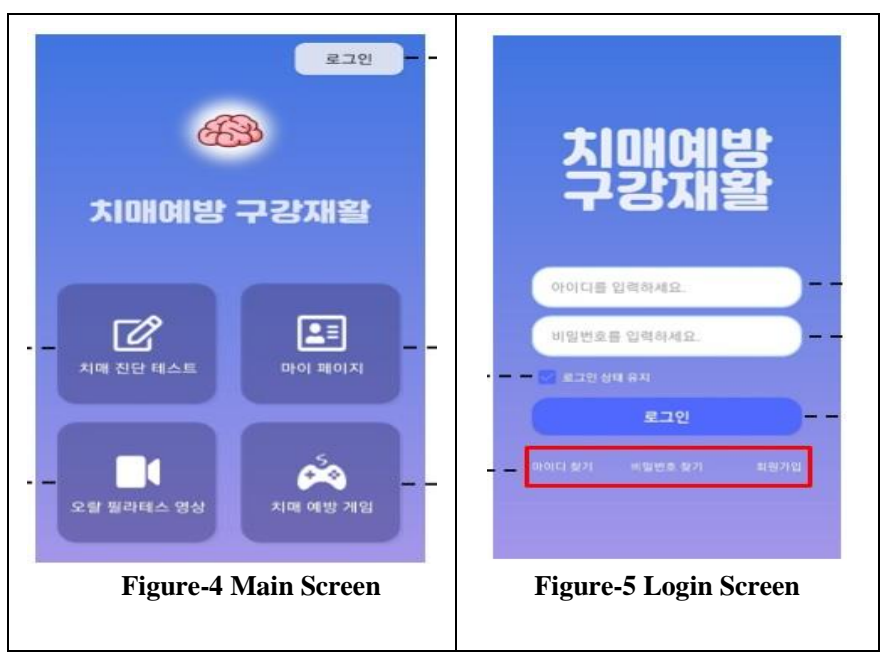




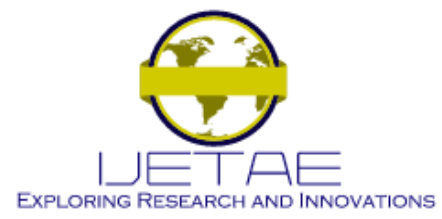

International Journal of Emerging Technology and Advanced Engineering

Website: www.ijetae.com (ISSN 2250-2459, ISO 9001:2008 Certified Journal, Volume 11, Issue 04, April 2021)

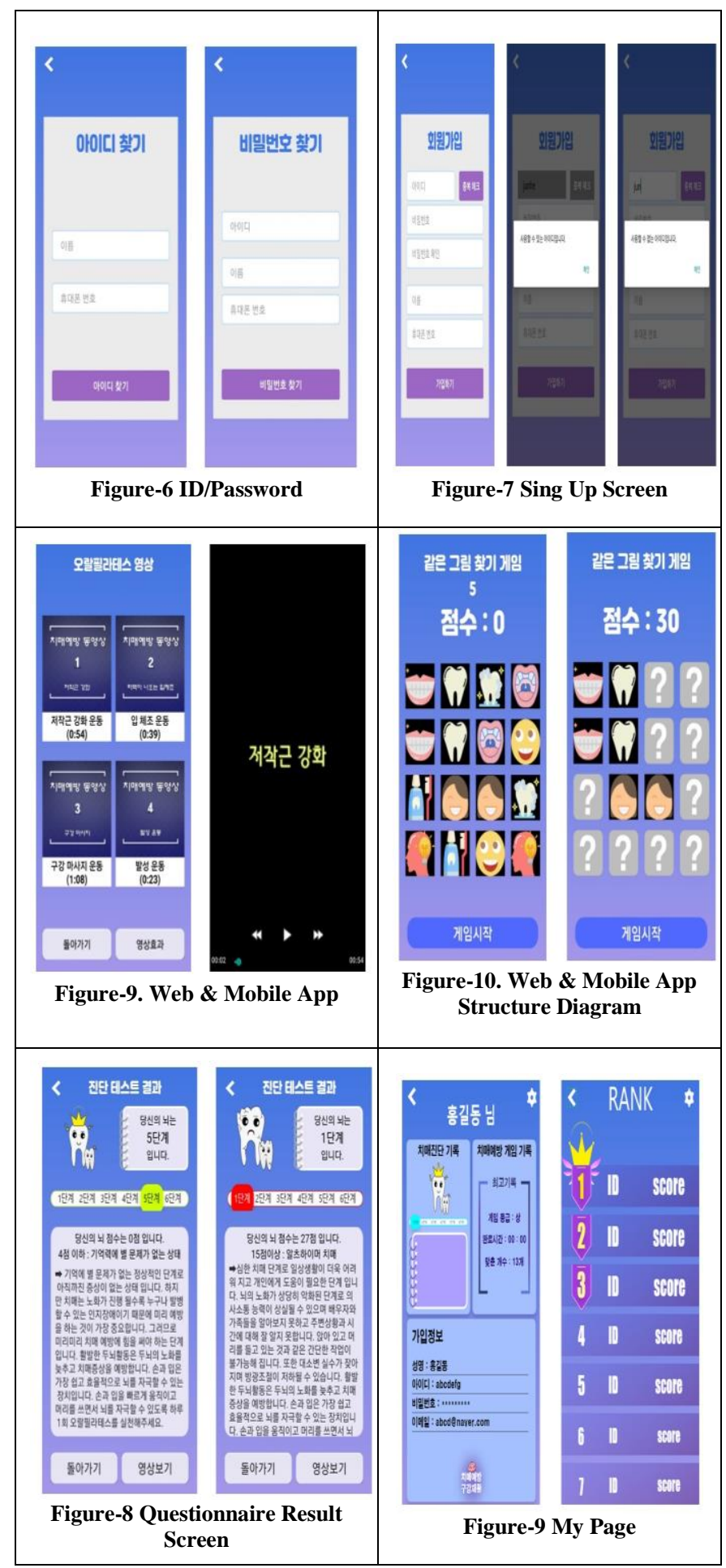

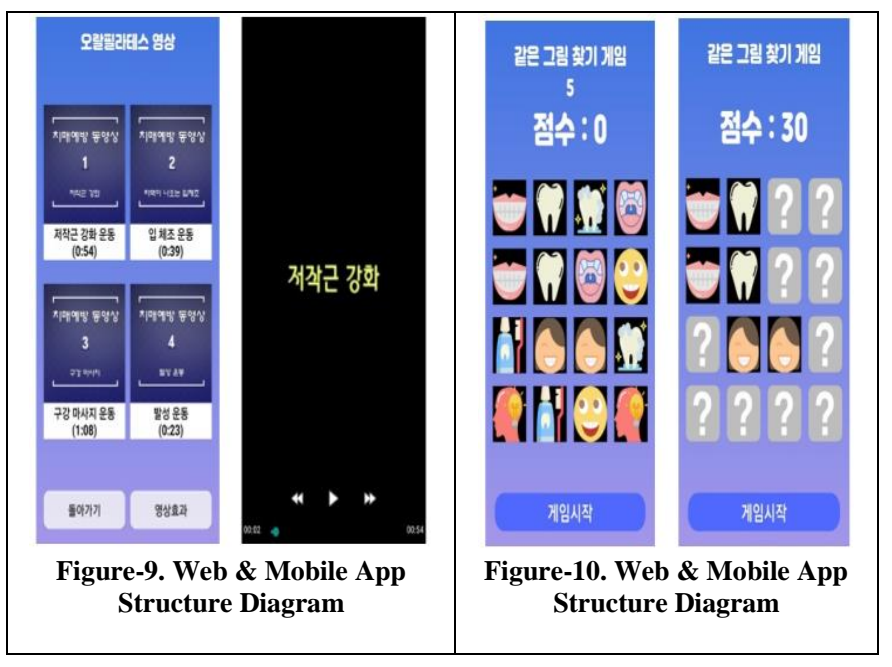

\section{CONCLUSION}

In this study, the cognitive function reinforcement system of oral rehabilitation concept was developed by applying IT technology and these research challenge can lead to new convergence studies. Also, the system is expected to contribute to reducing the social burden of dementia elderly health, preventing and managing elderly problems.

This application development is a new approach to improve the chewing and oral muscle function in the field of dental hygiene, thereby improving the cognitive function of the elderly and this application can be used as an oral rehabilitation training program because it was implemented to perform oral rehabilitation training and cognitive training applied to the actual treatment method mainly used in clinical practice, such as dentistry.

By combining the general cognitive rehabilitation treatment and prevention field of the demented elderly, oral healthcare field, and IT field, this application can be easily used by the elderly who are in the socially disadvantaged group.

\section{Acknowledgement}

This research was supported by the MISP(Ministry of Science, ICT \& Future Planning), Korea, under the National Program for Excellence in SW)supervised by the IITP(Institute for Information \& communications Technology Promotion) 


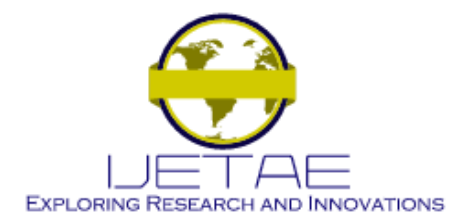

\section{International Journal of Emerging Technology and Advanced Engineering} Website: www.ijetae.com (ISSN 2250-2459, ISO 9001:2008 Certified Journal, Volume 11, Issue 04, April 2021)

\section{REFERENCES}

[1] National Statistical Office of Korea https://kosis.kr/statisticsList/statisticsListIndex.do?menuId=M_01_0 1\&vwcd=MT_ZTITLE\&parmTabId=M_01_01\&outLink=Y\&entrT ype $=\#$ content-group.

[2] Jin-Ah, Lee. 2016. An Exploratory Study on Development Strategies for Dementia Policy., Journal of Digital Convergence 14.11 Korea. pp.71-79.

[3] Jung-eun Lee., Il Sun Ko., 2018. The Relationship of Caregiving Appraisal and Family Function among Senile Dementia Patients' Families using In-home Services for the Long Term Care Insurance., Korea Convergence Society 9.8 Korea pp.319-330.

[4] Hojin Choi, Seung Hyun Kim., 2018. Policy of national responsibility and dementia care., Journal of the Korea Medical Association, 61(5), pp. 309-313

[5] Kyung-Lhi Kang., 2018. " Association between dementia and oral health." Journal of the Korean Dental Association 56.4 pp 218-230.

[6] Eun-seo Jung Yoon-young Choi, Kyeong-hee Lee., 2019 " A qualitative study on the present conditions and problems of oral health care in senile dementia patients"., Journal of Korean Society of Dental Hygiene ., 19.4 , 601-614.
[7] Hye-Bin Go, Min-Gyeong Kim, Jin-Young Kim, Hyun-Soo Kim, Young-Seo Park, Seung-Hyeon Seo, and Soo-Jeong Hwang. 2016., "The relationship between dementia and oral health in some elderly in Daejeon". Journal of Dental Hygiene Science, 16(6), 481-487.

[8] https://www.nid.or.kr/support/hi_list_1.aspx

[9] Young-Ju Cho, Hye-Suk Kim,, Jin-Hyuk Kim. 2016. " The Development of Brain Health Care Game Applications to prevent Digital Dementia." Journal of the Korea Society of Computer and Information., 21.12, 51-58.

[10] Seong-Min Yun, Hyo-Sun Choi, Myeon-Gyun Cho., 2014, Integration of Application Program for Dementia Diagnosis using Biometric Sensor and Oxygen Chamber., Korea Academy Industrial Cooperation Society, 15(5), 2953-2961.

[11] Jaewhan Yoo O, DoHyun Ahn, SeungHo Choun, Sung-Phil Heo (2019). Dementia Care System Using Virtual Reality with Nonwearable Sensing Technology, Journal of The Korea Society of Computer and Information. 27(1), 79-82.

[12] D Development of Health Care System for Elderly People with Dementia Based on Leap Motion Sensor Ji-Woo Shin · Ji-Soo Kim · Gwang-Soo · Byung-Gyu Kim* Dept. of IT Engineering, Sookmyung Women's University, Seoul 04310, Korea 